\title{
A Kuznets curve for recycling
}

\section{Working Paper}

\section{Author(s):}

Pittel, Karen

Publication date:

2006-05

\section{Permanent link:}

https://doi.org/10.3929/ethz-a-005229395

\section{Rights / license:}

In Copyright - Non-Commercial Use Permitted

Originally published in:

Economics Working Paper Series 06/52 


\title{
CER-ETH - Center of Economic Research at ETH Zurich
}

\section{A Kuznets Curve for Recycling}

\author{
Karen Pittel
}

Working Paper 06/52

(May 2006)

\section{Economics Working Paper Series}

\section{EIH}

Eidgenössische Technische Hochschule Zürich Swiss Federal Institute of Technology Zurich 


\title{
A Kuznets Curve for Recycling
}

\author{
Karen Pittel*
}

May 2006

\begin{abstract}
The paper aims at extending the debate on Environmental Kuznets Curves to the case of non-renewable resources and to discuss the driving forces that might give rise to EKC's in this case.

The paper at hand deviates from the standard EKC analysis in two ways: First, mostly EKC's are analyzed for flow variables. In this paper we argue that EKC's may very well arise for certain stock variables like minerals or waste. Second, most papers that provide a theoretical foundation for EKC's focus on assumptions like technological anomalies (e.g. increasing returns) or technological switches. We offer an alternative explanation by showing that EKC's might arise simply due to the combination of recycling and the rising scarcity of materials.

It is shown that an EKC for non-renewables might emerge during the transition to the long-run balanced growth path. Whether or not an EKC arises depends e.g. on initial conditions, but also on preferences and technology.

The assumptions made about the ability of recycling firms to internalize the interrelation between recycling decisions today and the future availability of recyclable waste matter with respect to the prerequisites for an EKC and the speed of convergence. Internalization furthermore implies that an economy can be caught in a poverty trap, i.e. it might not be able to converge to the long-run growth equilibrium if the initial endowment with resources and capital is too low.
\end{abstract}

Keywords: non-renewable resources, recycling, transitional growth, Environmental Kuznets Curve

JEL-code: Q32, Q53, O4, O13

${ }^{*}$ WIF - Institute of Economic Research, ZUE F12, ETH Zentrum, 8092 Zurich, Switzerland, email: kpittel@.ethz.ch 


\section{Introduction}

The last decade has witnessed an ever increasing interest in the Environmental Kuznets Curve (EKC) hypotheses. Postulating that environmental deterioration increases during early phases of economic development, yet decreases again in later stages, it has sometimes even be seen as the long-sought solution for environmental problems caused by economic development per se. Although this very optimistic view has faded, the topic in general should not be discarded so easily. Even though it remains dubitable whether an EKC exists with respect to an aggregate environmental indicator, the phenomenon has been observed empirically for a number of specific pollutants and indicators. Yet, a thorough theoretical foundation for the observed relation between income and environmental quality has long been missing. Only recently attention has gradually shifted to the theoretical underpinnings of the observed EKC's. Within the evolving literature, the EKC pattern has typically been attributed to either increasing returns to abatement (Andreoni/Levinson 2001, Egli/Steger 2005), technology switches (Smulders/Bretschger/Egli 2005) or sectoral changes (de Groot 1999).

The paper at hand deviates from this kind of standard EKC analysis in two ways: In many cases EKC's were observed for flow variables as $\mathrm{SO}_{2}$ - or $\mathrm{NO}_{x}$-emissions, less so for stock variables like household waste. In this paper we argue that EKC's may very well arise for certain stock variables. In our case this is the case for waste that arises from the use and discarding of materials like copper or iron. Besides deviating from the standard literature by regarding environmental stock variables, we furthermore consider an alternative explanation for the emergence of EKC's. Instead of relying on assumptions like technological anomalies (as ever increasing returns to scale in abatement) or technological switches, we show that EKC's might arise simply due to the combination of recycling and the rising scarcity of materials. Due to the different timing of the generation of waste and recycling, the waste stock might initially rise and then decline over time.

A phenomenon like this has, for example, been suggested for the case of copper. The potentially recyclable share of copper is close to $100 \%$, very little is lost due to dissipation. Remaining reserves have been estimated to amount to 470 MMT (US Geological Survey 2005 , p. 55) ${ }^{1}$ while the peak of production is projected at levels of 50 to 60 MMT per year for sometime between 2055 and 2085 (depending on the assumed scenario with respect to recycling technologies, population and income behavior, see Ayres et al. 2001). This necessarily implies that more and more of the demand has to be met by recycled materials.

\footnotetext{
${ }^{1}$ This estimation encompasses those resources which could presently be extracted or produced at reasonable costs. The complete resource base, i.e. those already identified resources that "meet specified minimum physical and chemical criteria related to current mining and production practices, including those for grade, quality, thickness, and depth" (US Geological Survey, p. 193) would amount to 940 MMT. This estimation additionally includes resources with the potential for becoming economically available within reasonable planning horizons.
} 
Taking into account that the copper used in production will often be bound in the produced goods for a considerable number of years, this suggests that "the recycling rate for copper will necessarily approach $100 \%$, probably before the end of the present century" (Ayres et al. 2001 , p. 96$){ }^{2}$

In the following we consider a very simple economy that employs a non-renewable resource, e.g. copper, in production. This material input can either stem from virgin resources or be produced from copper waste by recycling. Material inputs are produced by two types of firms: virgin resource extractors on the one hand and recycling firms on the other. As in the case of copper we abstract from dissipation processes and assume that the employed materials could completely be recovered from the produced output. ${ }^{3}$ Whether or not materials do return to the environment, i.e. to the stock of waste, depends on their usage: those goods that are used for investment in the capital stock, remain bound in the capital stock. Those which are part of the consumed output are released again, return to the waste stock and can be taken from the waste stock again for later recycling.

We explicitly include a material balance condition in order to integrate the material flows properly into the model. This condition which was also employed by Pittel et al. (2005) reflects Lavoisier's law by ensuring that every material that served as an input to production is accounted for during the entire material flow cycle, i.e. material can only be converted but never be destroyed. ${ }^{4}$

With respect to the recycling firms we make two types of assumptions about the externalities arising in the recycling sector. Firstly we assume that recycling firms do not take into account that at least part of the material they recycle will return to the waste heap after consumption. In this case firms implicitly consider materials to be a non-renewable resource. In a second scenario we modify this scenario by assuming that recycling firms are aware of back-flow of materials and consider this in their output and pricing decision. Consequently the price of recycled waste does not follow the Hotelling path anymore, but takes into account the quasi-renewability of the waste stock.

With respect to the remaining set-up of the model we choose the simplest framework possible as the focus of the paper is on the environmental dimension, i.e. the EKC property, rather than on the driving forces of growth. ${ }^{5}$

\footnotetext{
${ }^{2}$ The rising importance of recycling with respect to other resources such as aluminum, iron and lead, but also glas and paper is also stressed by e.g. van Beukering 2001, van Beukering/Bouman 2001, OECD 2001 and Fullerton/Kinnaman 2002.

${ }^{3}$ This is admittedly a special case that approximates reality only in a limited range of materials.

${ }^{4}$ In recent years, some attempts have been made to integrate recycling into a macroeconomic dynamic framework (Mainwaring 1995, Musu/Lines 1995, Huhtala 1999, Conrad 1999, di Vita 2001, Kuhn et al. 2003). But except for a few examples (e.g. Huhtala 1999) these approaches lack a sound material balance foundation.

${ }^{5}$ Examples of papers that focus more on growth and the implications of exhaustible resources being an essential input to production (although neither recycling nor material balances are considered), see e.g. Aghion/Howitt 1998, Scholz and Ziemes 1999, Schou 2001, 2002, Groth/Schou 2002, and Grimaud/Rougé
} 
We show that an EKC can, but not necessarily has to arise during the transition to the balanced growth path. Whether or not the waste stock follows a hump-shaped path depends on the parametrization, the endowments with virgin resources and waste and also the market structure and externalities arising in the recycling sector. Along the balanced growth path the waste stock is decreasing monotonically over time. As waste can be considered as a valuable resource in our model, not recycling part of it cannot be optimal in the long-run.

The paper proceeds as follows: The following section introduces the model. In section 3 we then take a short look at the balanced growth path of the economy. Subsequently, in section 4, shows under which circumstances an EKC might arise in general and derives the specific transitional dynamics of the model. Section 5 concludes the paper.

\section{The Model}

We consider a very simple closed economy which is in some respects close to the setup of Pittel et al. (2005). As in Pittel et al., an explicit material balance condition is considered for the material inputs employed in the economy. The material inputs originally stem from the essential input of a non-renewable resource in production. The part of the materials that is discarded as waste after consumption can later be recycled. Whether these materials already have been recycled or not, is of consequence for future recycling possibilities. The present paper deviates from Pittel et al. (2005) by simplifying the driving forces behind growth considerably. While in Pittel et al. (2005) growth is driven endogenously by $R \& D$ and gains from specialization, growth results in the paper at hand from exogenous technological change. This assumption is of course simplistic as technological advancements fall like manna from heaven. Yet, the aim of this paper is not to explain why and how growth is driven, but rather why and how an $\mathrm{EKC}$ with respect to material waste can arise. The causes and consequences that are decisive for this EKC pattern are unrelated to the source of growth. So, while it would be possible to draw the same conclusions from a more complicated endogenously driven growth model, ${ }^{6}$ it seems more straightforward to choose the simplest framework in which it is still possible to explain the forces leading to the EKC.

With respect to consumption the modelling is quite standard. The representative household derives utility from consumption $C$ and maximizes discounted lifetime utility 2003, 2005

${ }^{6}$ One possible option would i.e. be to extend the paper by Pittel et al. (2005) which focuses on the balanced growth path by an analysis of the transitional dynamics. Yet, applying their framework here would only add to analytical complexity without enhancing the understanding of the EKC pattern. 
with respect to its intertemporal budget constraint

$$
\begin{array}{lll}
\max _{c} & \int_{0}^{\infty} U(C(t)) e^{-\rho t} d t & U_{C}>0, U_{C C}<0 \\
\text { s.t. } & \dot{K}=\frac{d K}{d t}=r K-C &
\end{array}
$$

where $\rho$ is the discount rate. $K$ denotes household wealth which is equal to the stock of capital in the economy. The wage rate is given by $w$ while $r$ is the interest rate. For simplicity we assume that each consumer supplies one unit of labor inelastically. Household's preferences are of the CRRA-type and the instantaneous utility function reads

$$
U(C)=\frac{C^{1-\sigma}}{1-\sigma} \quad \sigma \neq 1, \quad \sigma>0 .
$$

Solving the standard optimization problem given by (1) and (2) results in the familiar Keynes-Ramsey rule

$$
g_{C}=\frac{1}{\sigma}(r-\rho) .
$$

There are three types of firms in the economy: Final output producers, resource extracting firms and recycling firms. All firms operate under perfect competition. The homogeneous final output is produced from labor $L$, capital $C$ and an index of material inputs $M$ with the production technology being given by:

$$
Y=A K^{\alpha} Z^{\beta} W_{R}^{\gamma}, \quad \alpha, \beta, \gamma>0 \quad \alpha+\beta+\gamma=1
$$

where $A$ denotes the level of technology which grows at the exogenously given constant rate $g_{A}$.

All materials that are available for production purposes in our economy originally stem from a stock of non-renewable virgin resources: Virgin materials are extracted from the given stock and used in production. Residuals of production processes and/or consumption are then discarded as waste. The accumulated waste can again be considered as a kind of 'ore pile' from which secondary materials are taken for recycling. The parameters $\gamma$ and $\delta$ show how productive a unit of the virgin resource is compared to a unit of recycled materials. By choosing a Cobb-Douglas type production function we implicitly assume both types of materials are essential to production. The Cobb-Douglas function should be viewed as a limit case of a more general technology.

Using (4), it can easily be seen that profit maximization of firms leads to the well known set of first order conditions:

$$
r=\alpha \frac{Y}{K}, \quad p_{Z}=\beta \frac{Y}{Z}, \quad p_{W_{R}}=\gamma \frac{Y}{W_{R}} .
$$

where $p_{Z}$ and $p_{W_{R}}$ denote the prices for virgin resources and recycled waste. 
Of the final output produced, one part is consumed while the rest is used for investive purposes. Assuming that capital is not depreciated in the course of production, the equilibrium condition for the capital market reads

$$
\dot{K}=Y-C, \quad 0<C<Y .
$$

As capital and consumption goods are produced by the same technology the share of materials in newly created capital goods is identical to the share of materials in consumer goods. If a unit of output is invested, the materials bound in this unit become bound in the capital stock and are not discarded as waste. Abstracting from depreciation here implies that those materials that are bound in capital are bound there forever. ${ }^{7}$ If an output unit is consumed however, its material content is discarded to the waste stock. Over time these residuals accumulate and can be used as the source of secondary materials for recycling. The only way to decrease the waste stock is to recycle waste and employ the recycled waste again in production. The material balance equation for this economy consequently reads $^{8}$

$$
\dot{W}=-W_{R}+\left(Z+W_{R}\right) \frac{C}{Y}
$$

At each point in time the share $\frac{C}{Y}$ of the materials employed in production returns to the waste pile while $W_{R}$ is taken of the waste stock for recycling. If more materials return than are taken of the pile, the waste pile increases over time while it decreases if more materials are recycled then discarded. An EKC conformable pattern would therefore require that at early stages of the development process the waste pile increases while it decreases in later periods.

It is assumed that at $t=0$ there exist a stock of the virgin resource $S_{0}$ as well as a stock of waste $W_{0}$ that has already been accumulated during past production periods. At each point of time the producers of final goods decide upon the amounts of virgin resources and recycled waste they employ in production. Intertemporal consumer preferences and technologies then determine the share of final products devoted to capital accumulation and consumption and therefore also decide on the amounts of waste generated at each point in time.

For simplicity we assume that no costs arise in the production of the two material inputs. This assumption is of course not entirely realistic, yet the inclusion of production costs in these sectors would again not add to the explanation the basic mechanism driving the emergence of an EKC curve.

With respect to the optimizing behavior of resource extracting firms it seems reasonable to assume that firms have no incentive to internalize the positive effect their provision of

\footnotetext{
${ }^{7}$ As the material content of output might change over time, different units of the capital stock can be heterogeneous with respect to their material intensity. As we made the additional restriction that $0<C<Y$ this feature can be ignored. If a shrinking economy were considered however, a vintage approach should be employed.

${ }^{8}$ For a more detailed derivation and motivation of the material balance condition see Pittel et al. (2005).
} 
virgin resources has on the reflux of materials onto the waste pile. Firms thus maximize intertemporal profits from resource extraction under the restriction of a finite stock of resources:

$$
\begin{aligned}
& \max _{Z} \int_{0}^{\infty} p_{Z} Z e^{-\int_{0}^{t} r(s) d s} d t \\
& \text { s.t. } \quad \dot{S}=-Z .
\end{aligned}
$$

The first-order and transversality conditions are given by

$$
\begin{aligned}
& p_{Z} e^{-\int_{0}^{t} r(s) d s}=-\lambda \\
& \dot{\lambda}=0 \\
& \lim _{t \rightarrow \infty} \lambda S=0
\end{aligned}
$$

where $\lambda$ denotes the costate variable. Using (10) to (12) we can derive the familiar Hotelling rule for the optimal price path of the exhaustible resource $Z$

$$
g_{p_{Z}}=r
$$

With respect to the behavior of the recycling firms we distinguish between the following two scenarios: First (Scenario 1), we assume that the recycling firms do not take into account that part of the materials they recycle returns to the waste pile after consumption, i.e. the development of the waste stock is in this case exogenous to the firms. The logic is that a single firm does not realize its own impact on the development of the waste stock as the market share of a single producer is very small. In the second scenario (Scenario 2), we assume that the reflux of materials is not exogenous to the firm. Even if the market share of a single firm is very small, this endogeneity could, e.g., result if firms are forced to take back their own waste after consumption.

As the recycling firms in Scenario 1 do not internalize the reflux of materials to the waste heap, the waste stock has the characteristics of a non-renewable resource to them. Consequently, their profit maximization is of the same type as the optimization faced by the virgin resource extractors, such that the price of $W_{R}$ also follows the Hotelling path. Yet, if firms internalize the reflux, the waste stock is a renewable resource to them. With respect to the optimal development of the price for recycled waste, $p_{W_{R}}$, this leads, as will be shown, to a modified version of the Hotelling rule.

As an example consider the reuse of scrap cars for recycling purposes. Assume that there exist firms that provide recycled car steel for intermediate products, in this case car bodies. Now two alternative scenarios can be thought of: a) Scrap cars are simply dumped on a general junkyard, such that the availability of recyclable steel from these cars and the original provision of recycled steel is not - in the eyes of a single firms directly linked. This case would be consistent with the first scenario in which the reflux of materials is considered to be exogenous to the firms. b) Automobile producers could 
be regulated in the sense that they have the obligation to take back the scrap cars of their own brand. Handing these cars down to the firms that originally provided the recycled steel then creates a direct link between the provision and the reflow of recycled materials, such that the reflow becomes endogenous to the recycling firms - as assumed in the second scenario.

The general optimization problem of the recycling firms can be written as

$$
\begin{gathered}
\max _{W_{R}} \int_{0}^{\infty} p_{W_{R}} W_{R} e^{-\int_{0}^{t} r(s) d s} d t \\
\text { s.t. } \quad \dot{W}=-W_{R}+\left(\bar{W}_{R}+Z\right) \frac{C}{Y} .
\end{gathered}
$$

When recycling firms do not internalize the reflux of materials this implies that $\bar{W}_{R}$ is exogenous to them. In this case profit maximization yields the following first order and transversality conditions:

$$
\begin{aligned}
& p_{W_{R}} e^{-\int_{0}^{t} r(s) d s}=-\omega_{1} \\
& \dot{\omega}_{1}=0 \\
& \lim _{t \rightarrow \infty} \omega_{1} W=0
\end{aligned}
$$

where $\omega_{1}$ denotes the costate variable for $W$ in Scenario 1. When recycling firms do internalize the reflux of materials, i.e. $\bar{W}_{R}=W_{R}$ is endogenous, optimization gives

$$
\begin{aligned}
& p_{W_{R}} e^{-\int_{0}^{t} r(s) d s}=-\omega_{2}\left(1-\frac{C}{Y}\right) \\
& \dot{\omega}_{2}=0 \\
& \lim _{t \rightarrow \infty} \omega_{2} W=0
\end{aligned}
$$

with $\omega_{2}$ being the costate variable for $W$ in this second scenario.

Combining (16) with (17) - resp. (19) with (20) - shows that it is optimal for recycling firms to exhaust the complete stock of waste for recycling purposes when time goes to infinity. As the waste stock is a source of productive inputs, firms have an incentive to exploit the profit possibilities associated with this stock of materials. Not recycling part of the waste and leaving it on the waste pile cannot be optimal as recycled materials are a scarce and essential input to production. Yet, it will be shown that the waste stock might increase temporarily in early stages of economic development, thus leading to an EKC for materials.

From (15) to (17) we can again show that the standard Hotelling rule also holds for the price of recycled waste in Scenario 1:

$$
g_{p_{W_{R 1}}}=r .
$$


From (18) to (20), however, it follows that in the second scenario the price of $W_{R}$ follows

$$
g_{p_{W_{R 2}}}=r+\frac{C}{Y-C}\left(g_{Y}-g_{C}\right)
$$

where (21) is enhanced by the additional term on the right. This term reflects in which way an additional unit of recycling today affects the development of the share of materials that can again by employed in recycling in the future. If, e.g., the savings rate rises over time $\left(g_{Y}-g_{C}>0\right)$, this implies that of the recycled and virgin resources used in production, a higher and higher share does not return to the waste heap, but is bound in capital. In this case a marginal increase of recycling has a negative effect on the reflux of materials. This increases the opportunity cost of extraction, thereby inducing firms to ask for a higher compensation for recycling. Consequently the growth rate of $p_{W_{R 2}}$ exceeds the interest rate. The described effect arises because the waste can be characterized as a renewable resource when the reflux of material is endogenized. Changes in the savings rate affect the 'regeneration' rate, i.e. the reflux of material, such that the Hotelling rule has to be enhanced by a 'regenerability' term. Along the balanced growth path, along which $g_{Y}-g_{C}=0$, this term vanishes as the savings rate is constant and we are back at the standard Hotelling rule (21).

\section{Balanced Growth Path}

For the given economy the derivation of the decentralized balanced growth path (BGP) ${ }^{9}$ is quite straightforward due to the simple structure of the model. Nevertheless the results are interesting in two respects: On the one hand it can be shown that the growth rate of output as well as the development of the waste stock along the balanced growth path do not depend on whether or not the waste stock externality described above is internalized by the firms or not. On the other hand it is interesting to note that a higher productivity of the material inputs actually hurts growth.

With respect to the price for virgin resources and also the price of recycled waste in Scenario 1, we have already shown in the previous section that they always grow at the interest rate. As we have also seen, this does not have to hold with respect to the price of recycled waste in Scenario 2, see (22). Yet, as along the BGP consumption and output grow at the same rate, we can easily see that in equilibrium the $p_{W_{R}}$ grows at the (constant) interest rate as well.

Expressing the production function (4) as well as the first order conditions for $Z$ and $W_{R}$ from (5) in terms of growth rates, considering the Hotelling rules and taking into account that along the BGP $g_{Y}=g_{K}$ has to hold, the equilibrium interest rate can be

\footnotetext{
${ }^{9}$ We define a growth path to be balanced and to represent a long-run equilibrium if all variables grow at constant rates.
} 
shown to equal

$$
\hat{r}=\frac{g_{A}}{\beta+\gamma}
$$

where a hat denotes the value of a variable along the BGP. Substituting this expression into (3) we get the equilibrium growth rate of output, capital and consumption

$$
\hat{g}=\frac{1}{\sigma}\left(\frac{g_{A}}{\beta+\gamma}-\rho\right) .
$$

As to be expected $\hat{g}$ depends positively on the rate of technical progress as an increase in $g_{A}$ raises the productivity of capital. The productivities of the material inputs, $\beta$ and $\gamma$, on the other hand affect the long-run growth rate negatively. The more productive virgin and recycled resources are, the more the decrease of the materials' input over time hurts growth.

Differentiating the first order conditions for $Z$ and $W_{R}$ in (5) with respect to time and equating the resulting expressions shows that the growth rates of the values of the two material inputs are equalized in equilibrium:

$$
g_{Z}+g_{p_{Z}}=g_{W_{R}}+g_{p_{W_{R}}} .
$$

Considering furthermore that both prices in (25) grow at the same rate, shows that in the long-run equilibrium the extraction of virgin resources and the amount of recycled waste have to grow at the same rates. Using (23) and (24), if follows that the balanced growth rates of the two material inputs are equal to

$$
\hat{g}_{Z}=\hat{g}_{W_{R}}=\frac{1}{\sigma}\left((1-\sigma) \frac{g_{A}}{\beta+\gamma}-\rho\right)
$$

which implies that $\frac{g_{A}}{(\beta+\gamma) \rho+g_{A}}<\sigma$ has to hold for the material inputs' growth rates to be negative. As it follows from the equation of motion of $S$, (9), that along the BGP $g_{Z}=g_{S}<0$ while (25) implies that $g_{Z}=g_{W_{R}}$, the negativity of $g_{Z}$ and $g_{W_{R}}$ has to hold in equilibrium.

With respect to the development of the waste pile, we already know from the transversality conditions (17) and (20) respectively, that $W$ has to decrease over time for the equilibrium to be optimal. Dividing (7) by $W$ and differentiating the resulting expression with respect to time shows furthermore that in the long-run equilibrium the growth rates of the waste stock and the growth rate of the recycled waste have to be equal $g_{W}=g_{W_{R}}$.

\section{Transitional Dynamics}

Assume now that the starting values of the economic variables are not such that the economy is and will forever remain on the balanced path. We will show that in this case the transitional dynamics can give rise to an EKC compatible development of the waste stock. Let us first take a look at general conditions that have to hold for an EKC to arise and then turn to the specific transitional dynamics of this model. 


\subsection{Prerequisites for an EKC}

A humped shape curve for the waste stock would imply that waste accumulates at a positive rate early in the transition process while in later stages the accumulation rate becomes negative. As optimizing firms will exhaust the waste pile when time goes to infinity, we already know that at some development stage the accumulation rate will become negative. By looking at the equation of motion for waste

$$
\begin{aligned}
\dot{W} & =-W_{R}+\left(Z+W_{R}\right) \frac{C}{Y} \\
& =-\left(1-\frac{C}{Y}\right) W_{R_{0}} e^{\int_{0}^{t} g_{W_{R}}(\tau) d \tau}+\frac{C}{Y} Z_{0} e^{\int_{0}^{t} g_{Z}(\tau) d \tau}
\end{aligned}
$$

it becomes furthermore clear that whether the waste stock is increasing or decreasing in early stages depends on the development of the consumption share of output, initial resource extraction and recycling, and and the development of the price for virgin resources and recycled waste. The initial values of the variables as well as their development over time depend crucially on the assumptions made about the initial stocks in the economy.

Given that recycling firms take the development of $W$ to be exogenous (Scenario 1), the prices of both material resources rise at rate the same rate, $r$, and (27) can be rewritten as

$$
\dot{W}=e^{\int_{0}^{t}\left(g_{Y}(\tau)-r(\tau)\right) d \tau}\left[-\left(1-\frac{C}{Y}\right) W_{R_{0}}+\frac{C}{Y} Z_{0}\right],
$$

such that the sign of $\dot{W}$ depends solely on the term in brackets. It can easily be seen that, if initial recycling is relatively low compared to virgin resource extraction while $\frac{C}{Y}$ is relatively high and then decreases during transition, the term in brackets might initially be positive and then become negative over time. This would imply that, while waste might be accumulating during early stages of economic development, it might 'decumulate' in later stages, thereby leading to the familiar EKC pattern. Consequently, an EKC type of development would be more likely to arise in an economy in which the savings rate is initially low. As a necessary condition for an EKC to arise, an increasing savings rate during transition can be identified. This seems to be in line with the empirics of economic development. While early in the development process the savings rate tends to be low, when countries grows richer, households rise the part of their income devoted to savings. With respect to the ratio between recycling and virgin resource extraction, it remains constant due to our assumption that the two material inputs are perfect substitutes and due to the fact that their prices increase at the same rate.

Rewriting (28) in terms of initial values and growth rates only, we can show that for an EKC to arise, the following condition has to hold for some $t<\bar{t}$ where $\bar{t}$ marks the point in time when the stock of waste becomes maximal:

$$
e^{\int_{0}^{t} g_{Y}-g_{C}}-\frac{C_{0}}{Y_{0}}<\frac{Z_{0}}{W_{R_{0}}} \frac{C_{0}}{Y_{0}}
$$


This condition is rather intuitive as it implies that an EKC arises only if initial resource extraction is not too low compared recycling. If at $t=0$ recycling is already quite high, the peak of the EKC has already been passed. During the transition the term on the LHS rises over time, such that in the long run $\dot{W}<0$ holds.

If recyclers take the reflux of materials to be endogenous, transitional dynamics may also be compatible with an EKC. Due to the different development of the prices for recycled waste and virgin resources during the transition, an EKC might even arise if the savings rate is decreasing over time. Recalling the pricing rule for recycled waste, (22), (27) can now be rewritten as

$$
\dot{W}=e^{\int_{0}^{t}\left(g_{Y}(\tau)-r(\tau)\right) d \tau}\left[-\left(1-\frac{C}{Y}\right) W_{R_{0}} e^{-\int_{0}^{t} \frac{C}{Y-C}\left(g_{Y}-g_{C}\right) d \tau}+\frac{C}{Y} Z_{0}\right] .
$$

Consider a decrease of $\frac{C}{Y}$ during transition, which was identified as a necessary condition for an EKC to arise in Scenario 1. In this case the increase in the savings rate induces the growth rate of $p_{W_{R}}$ to exceed the interest rate, i.e. the price for recycled materials rises faster during the transition than the price for virgin resources. Compared to Scenario 1, the input of recycled waste in relation to virgin resource extraction now changes during transition. Over time, when the savings rate approaches its long-run value, the growth rates of the two material inputs converge and along the balanced path the two extraction rates are again equal.

Rewriting (30) in terms of initial values and growth rates shows that for an EKC to arise

$$
\left(e^{\int_{0}^{t} g_{Y}-g_{C}}-\frac{C_{0}}{Y_{0}}\right) e^{-\int_{0}^{t} \frac{C}{Y-C}\left(g_{Y}-g_{C}\right)}<\frac{Z_{0}}{W_{R_{0}}} \frac{C_{0}}{Y_{0}}
$$

has to hold for some $t<\bar{t}$.

\subsection{Transitional dynamics and stability}

In the following we take a look at the local stability properties and the linearized saddle path along which the system converges to the steady state. From the analytical results of this analysis we can draw some conclusions about when economic development might give rise to an EKC.

\subsubsection{Local stability properties}

\section{Scenario 1}

To analyze the transitional dynamics we first rewrite the dynamic system in variables that are constant along the BGP. For the economy at hand this stationary system consists of five differential equations. Let us define the following new variables

$$
c_{k}=\frac{C}{K}, \quad y_{k}=\frac{Y}{K}, \quad z_{s}=\frac{Z}{S}, \quad w_{R w}=\frac{W_{R}}{W}, \quad z_{w}=\frac{Z}{W}
$$


which all grow at a rate of zero along the BGP. Expressing the dynamic system in these variables gives rise to the following system of differential equations:

$$
\begin{aligned}
\dot{y}_{k} & =\left(\frac{g_{A}}{\alpha}-(1-\alpha) y_{k}\right) y_{k} \\
\dot{c}_{k} & =\left(c_{k}-\frac{\sigma-\alpha}{\sigma} y_{k}-\frac{\rho}{\sigma}\right) c_{k}
\end{aligned}
$$

plus three recursive equations of motion:

$$
\begin{aligned}
\dot{z}_{s} & =\left(\frac{g_{A}}{\alpha}-y_{k}+z_{s}\right) z_{s} \\
\dot{w}_{r w} & =\left(\frac{g_{A}}{\alpha}-y_{k}+w_{R w}-\left(w_{R w}+z_{w}\right) \frac{c_{k}}{y_{k}}\right) w_{R w} \\
\dot{z}_{w} & =\left(\frac{g_{A}}{\alpha}-y_{k}+w_{R w}-\left(w_{R w}+z_{w}\right) \frac{c_{k}}{y_{k}}\right) z_{w} .
\end{aligned}
$$

As (32) and (33) do not depend on $z_{s}, w_{R w}$ and $z_{w}$, we only consider these two equations in order to establish the stability properties of the system. Linearizing (32) and (33) and evaluating them at the steady state gives

$$
\left(\begin{array}{c}
\dot{c}_{k} \\
\dot{y}_{k}
\end{array}\right)=\left(\begin{array}{cc}
\hat{c}_{k} & \left(\frac{\alpha}{\sigma}-1\right) \hat{c}_{k} \\
0 & -(1-\alpha) \hat{y}_{k}
\end{array}\right)\left(\begin{array}{c}
c_{k}-\hat{c}_{k} \\
y_{k}-\hat{y}_{k}
\end{array}\right)=D_{N I}\left(\begin{array}{c}
c_{k}-\hat{c}_{k} \\
y_{k}-\hat{y}_{k}
\end{array}\right)
$$

with

$$
\hat{y}_{k}=\frac{g_{A}}{(1-\alpha) \alpha}, \quad \hat{c}_{k}=\frac{\rho}{\sigma}+\frac{\sigma-\alpha}{\sigma} \frac{g_{A}}{(1-\alpha) \alpha} .
$$

A necessary and sufficient condition for the system to be saddle-path stable is $\left|D_{N I}\right|<0$ which can easily be seen to hold for (37) with $\left|D_{N I}\right|=-(1-\alpha) \hat{y}_{k} \hat{c}_{k}<0$. Making use of the characteristic equation, the stable negative eigenvalue of the non-integrated scenario $\eta_{N I}$ can be shown to equal

$$
\begin{aligned}
\eta_{N I} & =\frac{1}{2}\left(\frac{\rho}{\sigma}-\frac{1-\sigma}{\sigma} \alpha \hat{y}_{k}\right)-\frac{1}{2} \sqrt{\left(\frac{\rho}{\sigma}-\frac{1-\sigma}{\sigma} \alpha \hat{y}_{k}\right)^{2}+4(1-\alpha) \hat{c}_{k} \hat{y}_{k}} \\
& =-\frac{g_{A}}{\alpha} .
\end{aligned}
$$

where $\frac{\rho}{\sigma}-\frac{1-\sigma}{\sigma} \alpha \hat{y}_{k}>0$ due to the transversality condition for $K$.

To visualize the dynamics of the system graphically, consider the isoclines and saddle path of the system. The isoclines are given by $y_{k}=\frac{\sigma}{\sigma-\alpha} c_{k}-\frac{\rho}{\sigma-\alpha}\left(\right.$ for $\left.\dot{c}_{k}=0\right)$ and $y_{k}=\frac{g_{A}}{\alpha(1-\alpha)}\left(\right.$ for $\left.\dot{y}_{k}=0\right)$. It can easily be seen that for $(\sigma-\alpha)>0$ the slope of $c_{k}$-isocline is positive and larger than unity (see Figure 1) while it is negative for $(\sigma-\alpha)<0$ (see Figure 2).

As we cannot solve for the saddle path of the system analytically, Figure 1 and 2 each depict a simulated saddle path SD which was numerically approximated using the the 


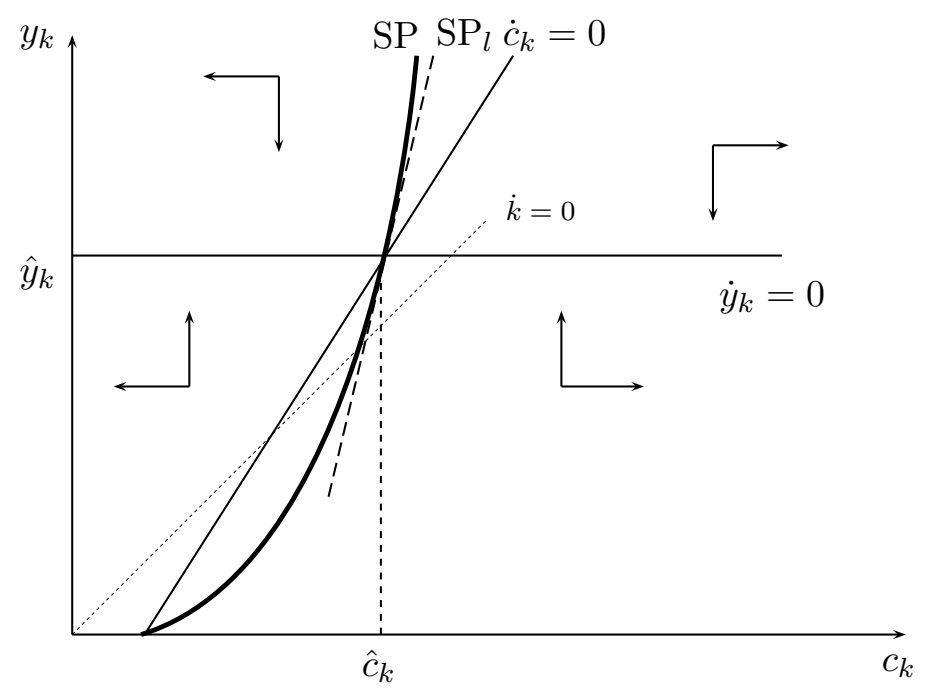

Figure 1: Transitional dynamics for $\sigma>\alpha$ (Scenario 1)

backward integration procedure as suggested by Brunner and Strulik (2002). Furthermore a linearized saddle path $\mathrm{SD}^{l}$

$$
\begin{aligned}
y_{k} & =\left[\frac{\sigma}{\sigma-\alpha}\left(1-\frac{\eta_{N I}}{\hat{c}_{k}}\right)\right] c_{k}-\left[\frac{\sigma}{\sigma-\alpha}\left(\hat{c}_{k}+\frac{\sigma-\alpha}{\sigma} y_{k}-\eta_{N I}\right)\right] \\
& =\left[\frac{\sigma}{\sigma-\alpha}\left(1+(1-\alpha) \frac{\hat{y}_{k}}{\hat{c}_{k}}\right)\right] c_{k}-\left[\frac{\sigma}{\sigma-\alpha}\left(\hat{c}_{k}+\alpha \frac{1-\sigma}{\sigma} \hat{y}_{k}\right)\right] .
\end{aligned}
$$

was computed (for the derivation see Appendix A) which gives an analytical expression for the dynamics around the steady state.

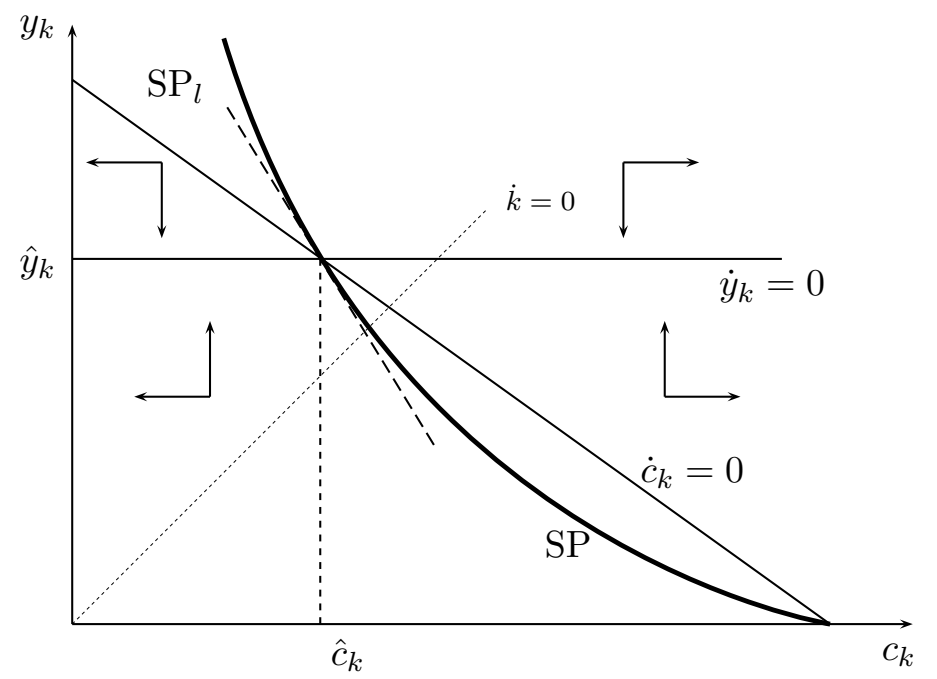

Figure 2: Transitional dynamics for $\sigma<\alpha$ (Scenario 1)

To see whether and when an EKC might arise during transition, consider Figures 1 and 2. From (40) we see that the slope of $\mathrm{SD}^{l}$ is positive (negative) for $\sigma-\alpha>0(\sigma-\alpha<0)$. 
For $\sigma>\alpha$ it can easily be established that the slope of the saddle path is larger than unity. This implies that for a transition from below, $y_{k}$ rises faster than $c_{k}$. Consequently $\frac{c_{k}}{y_{k}}=\frac{C}{Y}$ falls, i.e. the savings rate rises. This decline in the consumption-output ratio was identified in the previous section as a necessary prerequisite for an EKC to arise. Given that $\frac{c_{k}}{y_{k}}$ is initially above its long-run value, $y_{k}$ falls faster during transition than $c_{k}$ implying a decreasing savings rate. Consequently, for a transition from above EKC will not arise.

For $\sigma<\alpha$ the result is analogous. Starting from below the steady state, $c_{k}$ falls while $y_{k}$ rises during transition. The implicated fall of $\frac{C}{Y}$ might give rise to an EKC. For a transition from above, the savings rate again falls during transition, such that an EKC cannot arise.

But even if we are facing a transition from below, this does not necessarily imply an EKC-type development as this depends crucially on the strength of the increase in the savings rate. The stronger the increase, the stronger the effect on net recycling. How much the savings rate increases depends a) on the initial distance to the steady state and b) on the elasticity of consumption with respect to output along the saddle path, $\epsilon_{c, y}=\frac{d c_{k}}{d y_{k}} \frac{y_{k}}{c_{k}}$. The increase in the savings rate is the stronger, the lower the consumption elasticity along the saddle path.

We can now make use of the analytical expression for the linearized saddle path to show how the elasticity and therefore the scope of an EKC to arise depends on the model parameters.

From (38) and (40) it follows that the elasticity depends negatively on $\rho$, such that for higher impatience an EKC is more likely to arise. Given a higher value of $\rho$ households save less in the long as well as in the short run. Yet, the short-run reaction of the savings rate is stronger than the long-run reaction, such that for a higher $\rho$ the savings rate increases more sharply during transition.

With respect to the intertemporal elasticity of substitution, $\sigma$, its effect on the development of the savings rate is ambiguous. In the long-run the savings rate unambiguously falls, yet the effect on the development of the savings rate during transition is less clear. It can be shown that the short-run reaction of $s$ falls short of the long-run reaction given any initial value of $y_{k}$. It might even be the case that the initial savings rate rises for higher values of $\sigma$. As a consequence the elasticity of consumption with respect to output may rise or fall due to an increase of $\sigma$. While the long-run decrease of the savings rate lowers the consumption elasticity, this effect might be offset by the simultaneous decrease in 'real' impatience $\frac{\rho}{\sigma}$ following an increase in $\sigma$.

Finally, the transitional effect of a rise in the rate of technological progress, $g_{A}$, depends on $\sigma \lessgtr \alpha$. For $\sigma>\alpha$ an increase in $g_{A}$ induces a fall in the consumption elasticity thereby making an EKC more likely to arise. Yet, for $\sigma<\alpha$ the elasticity rises which lowers the scope for an EKC. The dependency of $\sigma \lessgtr \alpha$ mirrors the effects that an increase in 
$g_{A}$ exerts on the savings rate via the marginal productivity of capital. In the long-run, the faster rising productivity of capital leads - independently of $\sigma \lessgtr \alpha$ - to a higher savings rate, but in the short-run $s$ might rise or fall, depending on $\sigma \lessgtr \alpha$. For $\sigma<\alpha$ the substitution effect dominates the income effect. This implies that for a rise in $g_{A}$ the increase in the initial savings rate overshoots the long-run increase. Consequently, the increase of the savings rate during transition decreases with increasing $g_{A}$. For $\sigma>\alpha$ the opposite holds. The dominance of income over substitution effect leads to an initial decrease of savings. As a result the increase in the savings rate during transition is the stronger the higher $g_{A}$, raising the scope of an EKC to arise.

\section{Scenario 2}

Assume now that while resource extracting firms do not consider the reflux of materials in their optimization, waste recyclers do. With respect to the development of the price of the virgin resource, $g_{p_{Z}}=r$ still holds. Yet, with respect to the price of recycled waste, the optimal price path is given by (22). Taking this result into account we can now again write the dynamic system in terms of the stationary variables:

$$
\begin{aligned}
& \dot{y}_{k}=\left(\frac{1}{\alpha+\beta \frac{\frac{c_{k}}{y_{k}}}{1-\frac{c_{k}}{y_{k}}}}\left[g_{A}+\alpha\left(\alpha+\frac{\beta}{\sigma} \frac{\frac{c_{k}}{y_{k}}}{1-\frac{c_{k}}{y_{k}}}\right) y_{k}-\alpha c_{k}-\beta \frac{\frac{c_{k}}{y_{k}}}{1-\frac{c_{k}}{y_{k}}} \frac{\rho}{\sigma}\right]-y_{k}+c_{k}\right) y_{k} \\
& \dot{c}_{k}=\left(c_{k}-\frac{\sigma-\alpha}{\sigma} y_{k}-\frac{\rho}{\sigma}\right) c_{k}
\end{aligned}
$$

The equations of motion for $z_{s}, z_{w}$ and $w_{R w}$ are affected by the change in the time path of $g_{Y}$, but the resulting system of differential equations is still recursive in these variables.

By inspecting (41) the impact of the modified Hotelling rule for the behavior of the system during the transition becomes clear. As the modified pricing of recycled waste affects output growth via its effect on the input of recycled waste, the additional terms appearing in (41) compared to (32) are weighted by the production elasticity of recycled waste $\beta$. It can easily be seen that if all $\beta$-containing terms were missing we would be back at Scenario 1.

The term $B=\beta \frac{c_{k} / y_{k}}{1-c_{k} / y_{k}}$ reflects the effect that the modified pricing rule for $W_{R}$ exerts via the growth rate of recycling on the growth rate of output. Remember that the growth rate of recycling prices in Scenario 2 depends on $g_{Y}$ as well as on $g_{C}$ (see (22)). A ceteris paribus rise in output growth increases the growth rate of $g_{p_{W_{R}}}$ and thereby speeds up the exhaustion of the waste pile which reduces output growth. This effect is reflected by the appearance of $B$ in the denominator of (41). Furthermore the development of recycling prices in Scenario 2 depends on the growth rate of consumption. A ceteris paribus rise in $g_{C}$ lowers the growth rate of the price for recycled waste thereby affecting output growth positively. This effect is captured by the two additional, $\beta$ containing terms. This feedback effect of consumption growth on output growth is positive if consumption grows 
at a positive rate. ${ }^{10}$

Again we can calculate the negative eigenvalue, $\eta$, the linearized saddle path, $\mathrm{SD}^{l}$, and the isoclines for $c_{k}$ and $y_{k}$. While inspection of (42) already shows that the $c_{k}$-isocline remains the same as under Scenario $1, \dot{y}_{k}=0$ from (41) is now a quadratic function of $y_{k}$. This gives rise to an isocline which consists of two separate parts (see Figure 3 and 4) with two intersections of the $c_{k}$-isocline and the bipartite $y_{k}$-isocline. The intersection of the upper part of the $y_{k}$-isocline and $\dot{c}_{k}=0$ represents the steady state of the system which is - as in the previous section - given by $c_{k}=\hat{c}_{k}$ and $y_{k}=\hat{y}_{k}$. In contrast to this steady state, the intersection between $\dot{c}_{k}=0$ and (the lower part of) the $y_{k}$-isocline does not constitute an equilibrium. At this intersection $c_{k}=y_{k}=\frac{\rho}{\alpha}$, i.e. $\frac{C}{Y}=1$. Yet for a consumption-output ratio of unity (41) is not defined. This is due to the fact that for $\frac{C}{Y}=1$ no equilibrium on the market for recycled waste exists. For $\frac{C}{Y}=1$ the savings rate is equal to zero and no capital is accumulated. This implies that the entire recycled waste returns to the waste stock after consumption. Consequently no opportunity costs of recycling arise and on a competitive market the optimal price of recycled waste would be equal to zero. Yet for a price of zero no market equilibrium exists, as the demand for recycled waste becomes infinite while its supply is limited.

For the steady state $\left(\hat{c}_{k}, \hat{y}_{k}\right)$ we can now again determine the local stability properties. Linearizing (41) and (42) around the steady state $\hat{c}_{k}$ and $\hat{y}_{k}$ gives

$$
\left(\begin{array}{c}
\dot{c}_{k} \\
\dot{y}_{k}
\end{array}\right)=\left(\begin{array}{cc}
\hat{c}_{k} & \left(\frac{\alpha}{\sigma}-1\right) \hat{c}_{k} \\
d_{1} & d_{2}
\end{array}\right)\left(\begin{array}{c}
c_{k}-\hat{c}_{k} \\
y_{k}-\hat{y}_{k}
\end{array}\right)=D_{I}\left(\begin{array}{c}
c_{k}-\hat{c}_{k} \\
y_{k}-\hat{y}_{k}
\end{array}\right)
$$

with

$$
\begin{aligned}
d_{1} & =(1-h) \hat{y}_{k} \\
d_{2} & =-(1-\alpha) \hat{y}_{k}+(1-h) \frac{1-\sigma}{\sigma} \hat{y}_{k} .
\end{aligned}
$$

with $h=\alpha\left(\alpha+\beta \frac{\frac{\hat{c}_{k}}{\hat{y}_{k}}}{1-\frac{\hat{c}_{k}}{\hat{y}_{k}}}\right)^{-1}=\frac{\alpha\left(\hat{y}_{k}-\hat{c}_{k}\right)}{\alpha\left(\hat{y}_{k}-\hat{c}_{k}\right)+\beta \hat{c}_{k}}<1$.

$h$ reflects that ceteris paribus changes of $c_{k}$ and $y_{k}$ in Scenario 2 affect $\dot{y}_{k}$ also via feedback effects of the recycling market. Take $\left.\frac{\partial \dot{y}_{k}}{\partial c_{k}}\right|_{\hat{c}_{k}, \hat{y}_{k}}=\left.\dot{y}_{k} \frac{\partial g_{y_{k}}}{\partial c_{k}}\right|_{\hat{c}_{k}, \hat{y}_{k}}$ in (37) and (43) for example. Given that no feedback arises from a change in $c_{k}$ to the recycling markets (Scenario 1), a change in $c_{k}$ affects $g_{y_{k}}$ only via its effect on capital accumulation. On the one hand $g_{y_{k}}$ falls as $g_{Y}$ falls due to the slower accumulation of capital, on the other hand $g_{y_{k}}$ rises as the fall of $g_{K}$ directly increases the growth of the output-capital ratio.

\footnotetext{
${ }^{10}$ To see this consider the following:

$$
\alpha \frac{\beta}{\sigma} \frac{\frac{c_{k}}{y_{k}}}{1-\frac{c_{k}}{y_{k}}} y_{k}-\beta \frac{\frac{c_{k}}{y_{k}}}{1-\frac{c_{k}}{y_{k}}} \frac{\rho}{\sigma}=\beta \frac{\frac{c_{k}}{y_{k}}}{1-\frac{c_{k}}{y_{k}}} \frac{1}{\sigma}\left(\alpha y_{k}-\rho\right)=\beta \frac{\frac{c_{k}}{y_{k}}}{1-\frac{c_{k}}{y_{k}}} g_{C} .
$$
}




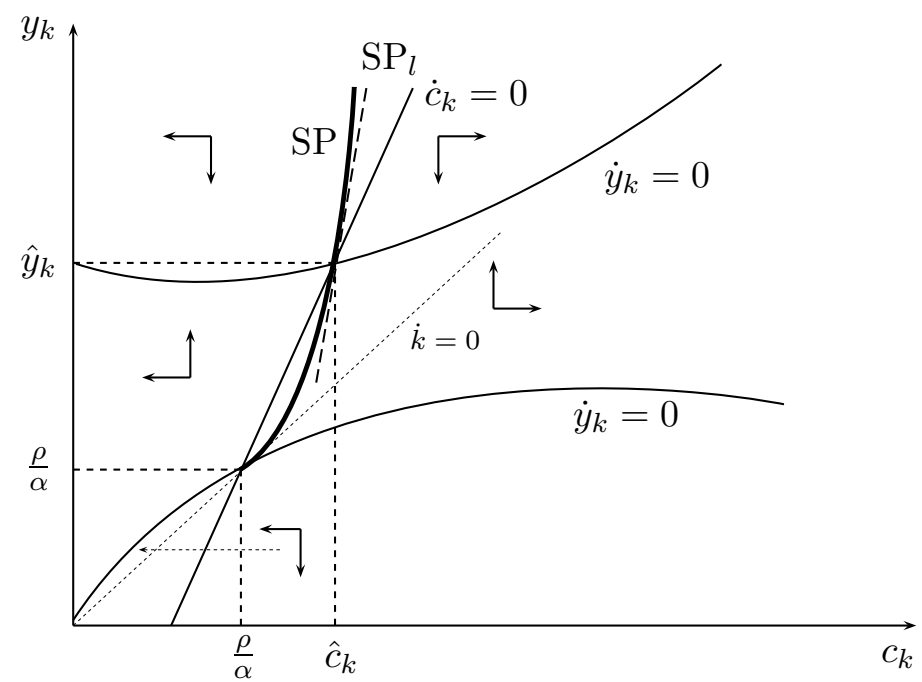

Figure 3: Transitional dynamics for $\sigma<\alpha$ (Scenario 2)

Without feedback effects of the recycling market, both effects exactly cancel for the given specification. In Scenario 2, however, the fall in output growth induced by the fall in $g_{K}$ is less strong. The feedback loop from output growth to recycling and vice versa implies that the reduction of $g_{Y}$ lowers the growth rate of recycling prices and thereby slows down the exhaustion of the waste pile which fosters output growth. The effect is dampened by the simultaneous decrease of the savings rate $s=1-\frac{c_{k}}{y_{k}}$. Summing up, the net effect of a change in $c_{k}$ on $g_{y_{k}}$ is now positive.

The line of argument for $\left.\frac{\partial \dot{y}_{k}}{\partial y_{k}}\right|_{\hat{c}_{k}, \hat{y}_{k}}=\left.\dot{y}_{k} \frac{\partial g_{y_{k}}}{\partial y_{k}}\right|_{\hat{c}_{k}, \hat{y}_{k}}$ is analogous. In both scenarios the term $-(1-\alpha) \hat{y}_{k}$ reflects that a change of $y_{k}$ affects capital accumulation negatively. In Scenario 1 this constitutes the only link between $\dot{y}_{k}$ and $y_{k}$. The difference between Scenario 1 and 2 arises due to the effect of a change in $y_{k}$ on the marginal product of capital. In Scenario 2 this affects the development of $y_{k}$ due to the direct link between consumption and output growth. Consider for example a rise in $y_{k}$. Due to the higher marginal product of capital, consumption growth rises or falls depending on whether the income or substitution effect dominates $(\sigma \gtrless 1)$. Given that, for example, the substitution effect dominates $(\sigma<1), g_{C}$ rises and accelerates the increase of output growth and therefore $\dot{y}_{k}$.

The determinant of $D_{I}$ can again be shown to be negative:

$$
\left|D_{I}\right|=-h(1-\alpha) \hat{c}_{k} \hat{y}_{k}<0
$$

such that the system is still locally saddle-path stable. Employing again the backward integration procedure shows that the local stability property extends to the global case for $y_{k}>\frac{\rho}{\alpha}$ (see the simulated saddle paths $S P$ in Figure 3 and Figure 4).

The system only converges to the steady state if the initial $y_{k}$ exceeds $\frac{\rho}{\alpha}$. Consequently, if an economy is initially so poorly endowed with physical as well as material resources 


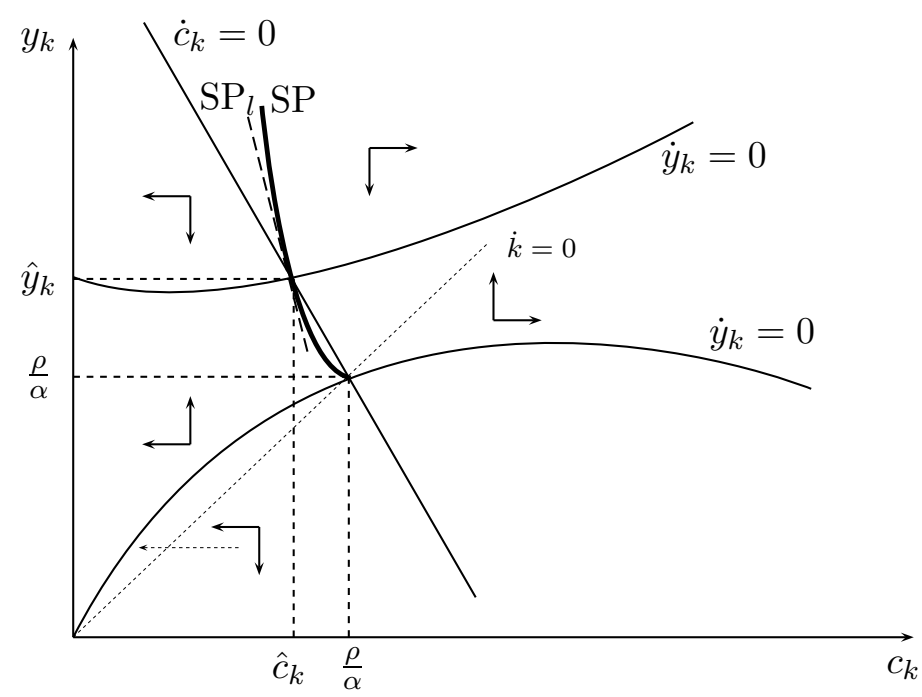

Figure 4: Transitional dynamics for $\sigma<\alpha$ (Scenario 2)

that an output-capital-ratio of $y_{k}>\frac{\rho}{\alpha}$ cannot be reached, the economy never converges to the long-run growth equilibrium. Given that $C / Y<1$ (as assumed), the growth rate of capital exceeds the growth rate of consumption in the long-run and the consumptioncapital-ratio goes to zero, as can be seen from the arrows in Figure 3 and 4 . If the economy even starts below the lower part of the $y_{k}$-isocline, but above $\dot{k}=0$, capital growth first dominates output growth until the isocline is passed and the output-capital ratio starts to rise. Over time the economy converges to $\left(c_{k}, y_{k}\right)=\left(0, \hat{y}_{k}\right) .{ }^{11}$

If we abstract for a moment from the assumption $C<Y$ and allow for capital decumulation, it becomes clear that in Scenario 1, even an economy that is poorly endowed with material resources and physical capital can always jump onto the saddle path and converge to the long-run equilibrium. Initially it may face a shrinking economy with negative consumption, capital and output growth, but, when the marginal product of capital has increased enough to render it attractive for households to save, growth becomes positive and the economy converges towards its long-run growth equilibrium.

In Scenario 2 the situation of a poorly endowed economy is worse. The development of a country that initially possesses too little material resources and physical capital can be compared to a kind of poverty trap that makes it impossible for the economy to reach a long-run growth equilibrium. Given an initial $\frac{Y}{K}<\frac{\rho}{\alpha}$, the economy can either exhibit a relatively low initial consumption level, i.e. $\dot{k}>0$, in which case the economy develops in the above described way towards $\left(c_{k}, y_{k}\right)=\left(0, \hat{y}_{k}\right)$. Or it can start with a relatively high consumption level, such that $\dot{k}<0$. In this case the decumulation of capital implies that for every unit of output produced, more recycled waste than employed in production

\footnotetext{
${ }^{11}\left(c_{k}, y_{k}\right)=\left(0, \hat{y}_{k}\right)$ does not represent an equilibrium of the system. For $y_{k}=\hat{y}_{k}$, the consumers would prefer an consumption-capital ratio of $c_{k}=\hat{c}_{k}$, such that the economy would jump to its long-run equilibrium which would violate the Kenyes-Ramsey condition (3).
} 
returns to the waste heap. So the scarcity of waste is actually decreasing as the waste heap increases. In Scenario 1 this is of course also the case for a decumulating capital stock, but as firms do not realize the impact of their production decisions on the flow-back of materials to the waste stock, they still perceive waste to become more and more scarce over time. As they do not perceive the waste stock as a renewable resource, they set the price according to the Hotelling rule. In Scenario 2 firms do perceive the waste stock as a renewable resource and realize that when they recycle one more unit, more than this one unit returns to the waste stock. The waste stock increases and the optimal price for the recycled waste becomes negative. ${ }^{12}$ This could, e.g., be the case of a government which, in the face of an increasing waste stock, subsidizes recycling to induce firms to recycle more. Facing the increasing waste stock firms are paid to employ more recycled waste in production. Perceiving this as a form of further income firms do employ more recycled waste in production, but at the same time they decumulate capital in order to increase the waste stock further and be therefore eligible for more subsidies. We face a self-fulfilling prophecy: Recycling is subsidized because the waste stock increases and the waste stock increases because recycling is subsidized.

In this case, the internalization of the recycling market failure in Scenario 2 compared to Scenario 1 actually implies that economies in which recycling firms act oblivious, may be better of in the long-run. While they can, independently of their endowment with capital and materials, always converge to the long-run equilibrium, this does not hold in Scenario 2. So, knowing more might be not be an advantage in this case. Poor economies that start in the non-convergence region would face an increasing waste heap over time while an EKC or even continuously decreasing waste heap would not be attainable.

If $y_{k}(0)>\frac{\rho}{\alpha}$ the economy converges to the long-run equilibrium. For $\sigma>\alpha$, consumption, capital and output grow at a positive rate during a transition from below, and, as the slope of the saddle path exceeds one, an EKC curve might arise. Equivalently, an EKC type development is possible for $\sigma<\alpha$ and a transition from below.

The functional form for the linearized saddle path is again given by (40)

$$
y_{k}=\left[\frac{\sigma}{\sigma-\alpha}\left(1-\frac{\eta_{I}}{\hat{c}_{k}}\right)\right] c_{k}-\left[\frac{\sigma}{\sigma-\alpha}\left(\hat{c}_{k}+\frac{\sigma-\alpha}{\sigma} y_{k}-\eta_{I}\right)\right]
$$

with the eigenvalue equalling

$$
\eta_{I}=\frac{1}{2}\left(\frac{\rho}{\sigma}-h \frac{1-\sigma}{\sigma} \alpha \hat{y}_{k}\right)-\frac{1}{2} \sqrt{\left(\frac{\rho}{\sigma}-h \frac{1-\sigma}{\sigma} \alpha \hat{y}_{k}\right)^{2}+4 h(1-\alpha) \hat{c}_{k} \hat{y}_{k} .}
$$

The transversality condition again ensures that the first term on the RHS is positive. Comparing (45) to (39) shows that the presence of $h$ constitutes the only difference between the negative eigenvalues in Scenario 1 and 2.

\footnotetext{
${ }^{12}$ It is of course the absence of recycling costs which implies that optimal prices become negative as soon as $\frac{C}{Y}>1$. Yet, even it recycling costs were considered, this situation would sooner or later arise, if marginal recycling costs were not increasing fast enough.
} 
It can be shown that - at least locally - the speed of convergence, as represented by $|\eta|$, might be higher or lower in Scenario 2 than in Scenario 1. If $\sigma<1$, i.e. when the substitution effect dominates the income effect, $|\eta|$ always rises such that convergence in the second scenario is always faster. ${ }^{13}$ In this case the savings rate falls due to the effect of the internalization on the marginal product of capital which induces the speed of convergence to rise. If $\sigma>1$ on the other hand, i.e. if the income effect outweighs the substitution effect, $|\eta|$ could also be lower than in the first scenario. Whether the speed of convergence rises or falls, depends crucially on $\beta$ which determines the strength of the feedback effect from the material resource markets on output and consumption development. The more productive recycled waste is in production, i.e. the higher $\beta$, the lower is $h$ and the more the recycling market feedbacks affects the development of the output-capital ratio over time (see also the discussion of (43)). Yet whether or not this results in a faster adjustment to the steady state, depends on whether the transmission of the feedback effects via $c_{k}$ or $y_{k}$ dominates. After rewriting (47) in terms of $d_{1}$ and $d_{2}$ and taking the derivative of the resulting expression with respect to $\beta$, it can be shown that for $\sigma>1$

$$
\frac{\mathrm{d} \eta_{N I}}{\mathrm{~d} \beta}=\frac{\partial \eta_{N I}}{\partial d_{2}} \frac{\mathrm{d} d_{2}}{\mathrm{~d} \beta}+\frac{\partial \eta_{N I}}{\partial d_{1}} \frac{\mathrm{d} d_{1}}{\mathrm{~d} \beta}=(+\cdot+)+(+\cdot-) \lesseqgtr 0 .
$$

In general, the higher the increase of $y_{k}$ that a rise of $y_{k}$ and $c_{k}$ induces, the faster the economy converges $\left(\frac{\partial \eta_{N I}}{\partial d_{2}}>0\right.$ and $\left.\frac{\partial \eta_{N I}}{\partial d_{1}}>0\right)$. Yet higher values of $\beta$ only raise the reagibility of $\dot{y}_{k}$ with respect to changes of $y_{k}$, while the reagibility with respect to $c_{k}$ falls. Depending on which effect is stronger, the speed of convergence rises or falls when recyclers internalize the feedback effects from recycling. For the intuition of the negative effect of $\beta$ on $d_{1}$ and thereby on the speed of convergence, see the explanation of (43) above.

For the EKC analysis the speed of convergence matters insofar that a faster transition process implies that the peak of the EKC from where on waste stocks start to decline is reached earlier.

\footnotetext{
${ }^{13}$ To see this consider the following: Postulating that the negative eigenvalue of Scenario 2 from (45), $\left|\eta_{I}\right|$ always exceeds the non-integrated $\left|\eta_{N I}\right|$ from (39) implies:

$$
a_{I}-\sqrt{a_{I}^{2}+b_{I}}>a_{N I}-\sqrt{a_{N I}^{2}+b_{N I}}
$$

with $a_{N I}=\frac{\rho}{\sigma}-\frac{1-\sigma}{\sigma} \alpha \hat{y}_{k}, a_{I}=\frac{\rho}{\sigma}-h \frac{1-\sigma}{\sigma} \alpha \hat{y}_{k}, b_{N I}=4 h(1-\alpha) \hat{c}_{k} \hat{y}_{k}$ and $b_{I}=h b_{N I}$. We know that $b_{N I}>b_{I}$ and, for $\sigma<1, a_{I}>a_{N I}>0$. Consequently we can set $a_{I}=\sqrt{a_{I}^{2}}$ and $a_{N I}=\sqrt{a_{N I}^{2}}$. It is clear that if we can show (46) to hold for $b_{N I}=b_{I}$, it also holds for $b_{N I}>b_{I}$. By rearranging (46) we get

$$
\frac{\sqrt{a_{N I}^{2}+b_{I}}-\sqrt{a_{I}^{2}}}{\left(a_{N I}^{2}+b_{I}\right)-a_{N I}^{2}}>\frac{\sqrt{a_{I}^{2}+b_{I}}-\sqrt{a_{I}^{2}}}{\left(a_{I}^{2}+b_{I}\right)-a_{I}^{2}}
$$

which always holds because of the concavity of $\sqrt{x}, x \in \mathbb{R}$.
} 


\section{Conclusions}

The main objective of this paper was to extend the debate on Environmental Kuznets Curves to the case of non-renewable resources and to discuss the driving forces that might give rise to EKC's in this case.

It was shown that an EKC for non-renewables might arise during the transition to the long-run balanced growth path. As the driving force behind the emergence of an EKC, the rising scarcity of these resources in a growing economy was identified. The decreasing availability of virgin resources in combination with an increasing savings rate during the development of countries can induce the emergence of an EKC. The increase in the scarcity of resources results on the one hand from the overall limit on exhaustible resource stocks and on the other hand from the fact that during development more and more resources become bound in the man-made capital stock. These bound resources are consequently not available for future recycling and cannot be reused as an productive input in the future. Whether or not an EKC arises depends, e.g., on the stage of development an economy has reached at the beginning of the observed time horizon.

We showed furthermore that the assumptions made about the ability of recycling firms to actually observe and internalize the development of the waste stock matters. It not only influences under which prerequisites an EKC might arise, but also affects the speed with which the economy passes through the transitional stages towards a balanced growth path. Internalization of the interrelation between recycling decisions today and the future availability of recyclable waste also implies that an economy can be caught in a poverty trap, i.e. it might not be able to converge to the long-run equilibrium if initially too poorly endowed with resources and capital.

\section{Appendix: Derivation of Linearized Saddle Path}

To derive the linearized saddle path of (32) - (33) take the general locally stable solution

$$
\left(\begin{array}{c}
c_{k}-\hat{c}_{k} \\
c_{k}-\hat{c}_{k}
\end{array}\right)=\left(\begin{array}{c}
A e^{\eta t} \\
B A e^{\eta t}
\end{array}\right) .
$$

which gives

$$
\dot{c}_{k}=\eta A e^{\eta t}
$$

Using the equation of motion for $c_{k}$ from (37) we can now determine $A$. Equating the two expressions for $\dot{c}_{k}$

$$
\eta A e^{\eta t}=\left(c_{k}-\hat{c}_{k}\right) \hat{c}_{k}-\frac{\sigma-\alpha}{\sigma}\left(y_{k}-\hat{y}_{k}\right) \hat{c}_{k}
$$

and solving for $A$ gives

$$
A=\eta^{-1} e^{-\eta t}\left[\left(c_{k}-\hat{c}_{k}\right) \hat{c}_{k}-\frac{\sigma-\alpha}{\sigma}\left(y_{k}-\hat{y}_{k}\right) \hat{c}_{k}\right] .
$$


Substituting $A$ into (49), considering $\eta=-(1-\alpha) \hat{y}_{k}$, we can solve for $y_{k}$ :

$$
y_{k}=\left[\frac{\sigma}{\sigma-\alpha}\left(1+(1-\alpha) \frac{\hat{y}_{k}}{\hat{c}_{k}}\right)\right] c_{k}-\left[\frac{\sigma}{\sigma-\alpha}\left(\hat{c}_{k}+\alpha \frac{1-\sigma}{\sigma} \hat{y}_{k}\right)\right] .
$$

which is given in (40).

\section{References}

Aghion, P./Howitt, P. (1998), Endogenous Growth Theory, Cambridge, Mass.: The MIT Press.

Andreoni, J./Levinson, A. (2001), The Simple Analytics of the Environmental Kuznets Curve", Journal of Public Economics, 80, 269 - 286.

Ayres, R.U./Ayres, L.W./Radem I. (2002), The Life Cycle of Copper, its Co-Products and By-Products, Mining, Minerals and Sustainable Development, no. 24.

Brunner, M./H. Strulik (2002), Solution of Perfect Foresight Saddlepoint Problems: A Simple Method and Applications, Journal of Economic Dynamics and Control, 26, 737-753.

Conrad, K. (1999), Resource and waste taxation in the theory of the firm with recycling activities, Environmental and Resource Economics, 14, 217-242.

di Vita, G. (2001), Technological change, growth and waste recycling, Energy Economics, $23,549-567$.

Grimaud, A./Rougé, L. (2005), Polluting non renewable resources, innovation and growth: Welfare and environmental policy, Resource and Energy Economics, 27, 109-129.

Grimaud, A./Rougé, L. (2003), Non-renewable resources and growth with vertical innovations: optimum, equilibrium and economic policies, Journal of Environmental and Resource Economics, 45, 433-453.

De Groot, H.L.F. (1999), Structural Change, Economic Growth and the Environmental Kuznets Curve. A Theoretical Perspective, OCFEB Research Memorandum No. 9911, Erasmus University Rotterdam.

Groth, C./Schou, P. (2002), Can non-renewable resources alleviate the knife-edge character of endogenous growth?, Oxford Economic Papers, 54, 386-411.

Fullerton, D./Kinnaman, T.C. (2002), The Economics of Household Garbage and Recycling Behavior, Cheltenham, UK and Northampton, MA, US: Edward Elgar.

Huhtala, A. (1999), Optimizing production technology choices: conventional production vs. recycling, Resource and Energy Economics, 21, 1-18.

Kuhn, T./Pittel, K./Schulz, T. (2003), Recycling for sustainability - a long-run perspective?, International Journal of Global Environmental Issues, 3, 339-355. 
Mainwaring, L. (1995), Primary resource use and voluntary recycling schemes: Dynamic issues in a global context, Resource and Energy Economics, 17, 341-357.

Musu, I./Lines, M. (1995), Endogenous growth and environmental preservation, in: G. Boero and A. Silberston, eds., Environmental Economics: Proceedings of the European Economic Association at Oxford 1993, Oxford: St. Martin's Press.

OECD (2001), OECD Environmental Outlook, Paris: OECD.

Pittel,K./Amigues, J.-P./Kuhn, T. (2005), Endogenous Growth and Recycling: A Material Balance Approach, Economics Working Papers Series 05/37, ETH Zurich, February 2005 .

Scholz, C.M./Ziemes, G. (1999), Exhaustible resources, monopolistic competition and endogenous growth, Environmental and Resource Economics, 13, 169-185.

Schou, P. (2002), When environmental policy is superfluous: Growth and polluting resources, Scandinavian Journal of Economics, 104, 4, 605-620.

Schou, P. (2001), Polluting non-renewable resources and growth, Environmental and Resource Economics, 16, 2, 211-227.

Smulders, S./Bretschger, L./Egli, E. (2005), Economic Growth and the Diffusion of Clean Technologies: Explaining Environmental Kuznets Curves, Economics Working Paper Series 05/42, ETH Zurich.

US Geological Survey (2005), Mineral Commodity Summaries 2005, US Government Printing Office, Washington.

van Beukering, P.J.H. (2001), Recycling, International Trade and the Environment: An Emprirical Analysis, Dordrecht: Kluwer.

van Beukering, P.J.H./Bouman, M.N. (2001), Empirical evidence on recycling and trade of paper and lead in developed and developing countries, World Development, 29, $1717-1737$. 


\section{Working Papers of the Center of Economic Research at ETH Zurich}

(PDF-files of the Working Papers can be downloaded at www.cer.ethz.ch/research).

06/51 C. N. Brunnschweiler

Cursing the blessings? Natural resource abundance, institutions, and economic growth

06/50 C. Di Maria and S. Valente

The Direction of Technical Change in Capital-Resource Economics

06/49 C. N. Brunnschweiler

Financing the alternative: renewable energy in developing and transition countries

06/48 S. Valente

Notes on Habit Formation and Socially Optimal Growth

06/47 L. Bretschger

Energy Prices, Growth, and the Channels in Between: Theory and Evidence

06/46 M. Schularick and T.M. Steger

Does Financial Integration Spur Economic Growth? New Evidence from the First Era of Financial Globalization

05/45 U. von Arx

Principle guided investing: The use of negative screens and its implications for green investors

05/44 Ch. Bjørnskov, A. Dreher and J.A.V. Fischer

The bigger the better? Evidence of the effect of government size on life satisfaction around the world

05/43 L. Bretschger: Taxes, Mobile Capital, and Economic Dynamics in a Globalising World

05/42 S. Smulders, L. Bretschger and H. Egli

Economic Growth and the Diffusion of Clean Technologies: Explaining Environmental Kuznets Curves

05/41 S. Valente

Tax Policy and Human Capital Formation with Public Investment in Education

05/40 T.M. Steger and L. Bretschger

Globalization, the Volatility of Intermediate Goods Prices and Economic Growth

05/39 H. Egli

A New Approach to Pollution Modelling in Models of the Environmental Kuznets Curve

$05 / 38$ S. Valente

Genuine Dissaving and Optimal Growth 
05/37 K. Pittel, J.-P. Amigues and T. Kuhn, Endogenous Growth and Recycling: A Material Balance Approach

05/36 L. Bretschger and K. Pittel

Innovative investments, natural resources, and intergenerational fairness: Are pension funds good for sustainable development?

04/35 T. Trimborn, K.-J. Koch and T.M. Steger

Multi-Dimensional Transitional Dynamics: A Simple Numerical Procedure

04/34 K. Pittel and D.T.G. Rübbelke

Private Provision of Public Goods: Incentives for Donations

04/33 H. Egli and T.M. Steger

A Simple Dynamic Model of the Environmental Kuznets Curve

04/32 L. Bretschger and T.M. Steger

The Dynamics of Economic Integration: Theory and Policy

04/31 H. Fehr-Duda, M. de Gennaro, R. Schubert

Gender, Financial Risk, and Probability Weights

03/30 T.M. Steger

Economic Growth and Sectoral Change under Resource Reallocation Costs

03/29 L. Bretschger

Natural resource scarcity and long-run development: central mechanisms when conditions are seemingly unfavourable

03/28 H. Egli

The Environmental Kuznets Curve - Evidence from Time Series Data for Germany

03/27 L. Bretschger

Economics of technological change and the natural environment: how effective are innovations as a remedy for resource scarcity?

03/26 L. Bretschger, S. Smulders

Sustainability and substitution of exhaustible natural resources. How resource prices affect long-term R\&D-investments

03/25 T.M. Steger

On the Mechanics of Economic Convergence

03/24 L. Bretschger

Growth in a Globalised Economy: The Effects of Capital Taxes and Tax Competition

02/23 M. Gysler, J.Kruse and R. Schubert

Ambiguity and Gender Differences in Financial Decision Making: An Experimental Examination of Competence and Confidence Effects 
01/22 S. Rutz

Minimum Participation Rules and the Effectiveness of Multilateral Environmental Agreements

01/21 M. Gysler, M. Powell, R. Schubert

How to Predict Gender-Differences in Choice Under Risk: A Case for the Use of Formalized Models

00/20 S.Rutz, T. Borek

International Environmental Negotiation: Does Coalition Size Matter?

00/19 S. Dietz

Does an environmental Kuznets curve exist for biodiversity? 